\title{
Evaluation of Papillo-Incisal Distance with Different Shapes of Incisive Papilla
}

\author{
Samarth Kumar Agarwal ${ }^{1}$, Romil Singhal ${ }^{2}$, Shraddha Pagia $^{3}$
}

\begin{abstract}
In today's world aesthetics is the primary concern for patients seeking prosthodontic treatment. The erroneous placement of the maxillary anterior teeth on the residual ridge has contributed more to the artificially senile appearance of the face than any other single factor. In the absence of pre-extraction records, the incisive papilla is an anatomic landmark that can be used as an aid for anterior tooth positioning in edentulous patients. An average distance has been described by various authors. This study aims to evaluate whether the shape of incisive papilla has any influence on this distance or not.
\end{abstract}

Keywords: Incisive Papilla, Central Incisor, Shape of Incisive Papilla, Papillo-incisal distance, mesioincisal point angle

\section{Introduction}

Consideration of appearance plays a important part in patient seeking prosthodontic treatment ${ }^{1}$. To achieve this, the dentist must know Nature's scheme for upper anterior teeth ${ }^{2,3}$.

The horizontal relationship between the incisive papilla and the maxillary central incisors in the dentulous is a guide to position the central incisor teeth as nearly as possible in their original location to restore labial contour in edentulous subjects $^{4-7}$. The center/middle or the base/posterior border of the papilla are mostly used as reference for papilla incisor measurements. During edentulous transformation as the papilla changes to round form, its center also changes. There is a shift in the center of the papilla from the dentulous to edentulous state ${ }^{8}$. In dentulous subjects incisive papilla is seen in various shapes and this change will be more in a long papilla compared to a short papilla. The shape of the incisive papilla in dentulous is investigated since it can influence the center of the edentulous papilla from the dentulous state ${ }^{8}$. Hence the present study will be carried out to investigate the distance between central incisor and different shapes of incisive papilla and to see whether measurements of central incisor to incisive papilla distance in dentate patients with different shapes of incisive papilla will affect average distance of maxillary anterior teeth arrangement while dealing with prosthodontic patients in dentulous arches in Moradabad population.

\section{Materials and Method}

This short study was carried on 49 samples. Inclusion criteria involve the subjects of 17-40 years of age who has normal healthy dentition, well aligned arches with all incisors, canines, first and second premolars present. First maxillary impressions was taken with irreversible hydrocolloid and the cast was poured using dental stone. The shape of incisive papilla was marked on the cast and recognized according to its shape. Then the mesioincisal point angle of central incisor and posterior border of incisive papilla was also marked on the cast and the distance between the mesioincisal point angle of central incisor and posterior border of incisive papilla was measured. All data were collected and statistically analyzed.

\section{Results}

Result of the study are shown in table 1. Seven shapes of incisive papilla were seen, out of which cylindrical shape was most common. Cylindrical shaped incisive papilla showed maximum distance with mean of 12.63 whereas round shaped papilla showed minimum distance with mean of 10.47 .

Table 1

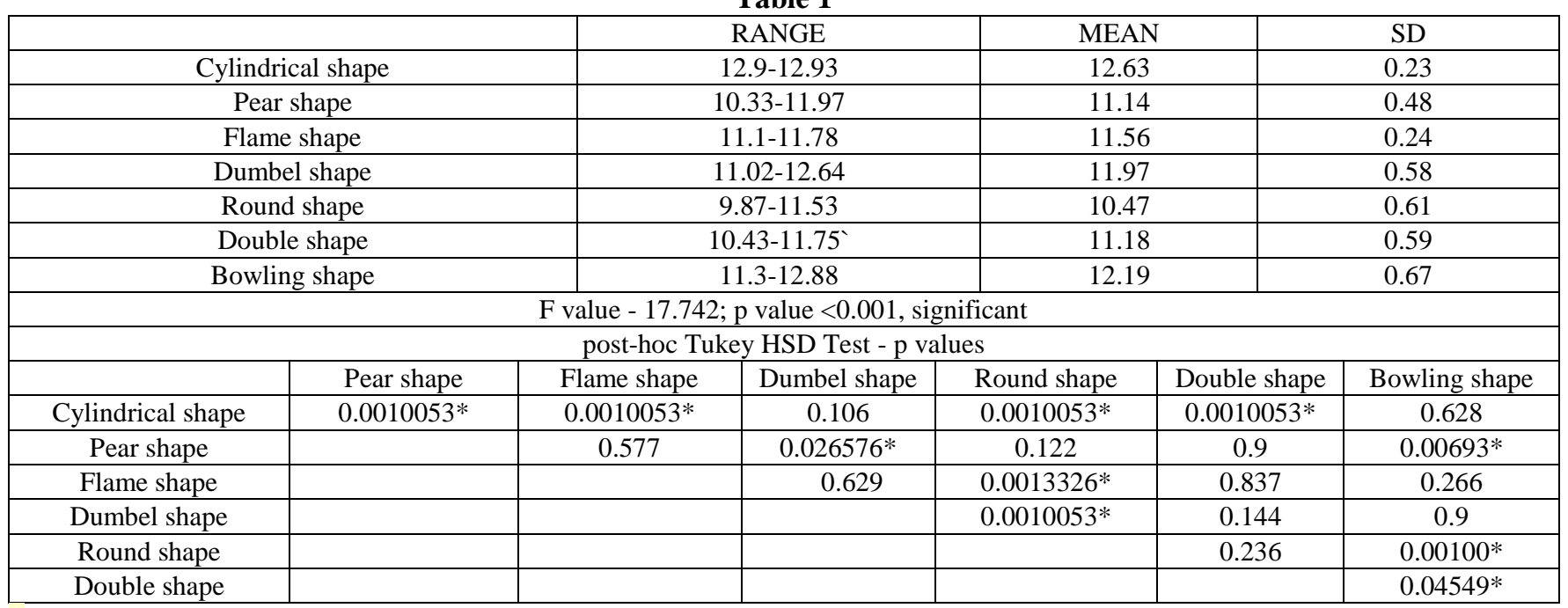




\section{International Journal of Science and Research (IJSR) \\ ISSN (Online): 2319-7064 \\ Index Copernicus Value (2013): 6.14 | Impact Factor (2014): 5.611}

The p-value corresponding to the F-statistic of one-way ANOVA is lower than 0.05 , suggesting that the one or more groups are significantly different. The Tukey HSD test comparison identify which of the pairs of groups are significantly different from each other. It is significant between cylindrical shape and other shape i.e. pear, flame, round, and double shaped papilla. It is also significant between pear shape and dumbel, and bowling shape papilla. It is also found significant between dumbel and round shape, and round and bowling shape, and double and bowling shape papilla.

\section{Discussion}

An average position of the maxillary anterior teeth to stable landmarks such as maxillary central incisor to incisive papilla distance has been mentioned as an important anthropometric tool facilitating prosthetic teeth arrangement in prosthodontics ${ }^{8}$. In the present study an effort was made to measure this distance in dentate patients with different shapes of incisive papilla. It was observed that the cylindrical shaped papilla had maximum central incisor to incisive papilla distance while the round shaped papilla had minimum distance. The shape of the incisive papilla was significantly affecting the average papilla- incisor distance. This is because the posterior border of incisive papilla changes with the shape of incisive papilla ${ }^{9}$. Round shaped papilla had border near to the central incisor while cylindrical shaped incisive papilla had border far from central incisor. Another reason for this difference may be arch form. Distance between incisive papilla and central incisors vary in different arch form. So, further studies are needed to combine different arch form with shapes of incisive papilla ${ }^{10}$.

\section{Conclusion}

The shape of the incisive papilla affects the distance between central incisor and incisive papilla affecting the placement of maxillary central incisor in edentulous patient . This can use as a guide for placement of anterior teeth with different shapes of papilla.

\section{References}

[1] Krajicek DD. Simulation of natural appearance. J Prosthet Dent 1962;12(1):28-33.

[2] Lau GCK, and Clark RFK. The relationship of the incisive papilla to the maxillary central incisors and canine teeth in southern Chinese. J Prosthet Dent 1993;70(1):86-93.

[3] Pound E. Lost-Fine Arts in the Fallacy of the Ridges. J Prosthet Dent 1954;4(1):6-16.

[4] Harper RN. The incisive papilla-basis of technic to reproduce the positions of key teeth in prosthodontia. J Dent Res 1948; 27:661-668.

[5] McGee GF. Tooth placement and base contour in denture construction. J Prosthet Dent 1960; 10:651-657.

[6] Hickey JC, Boucher CO, Woelfel JB. Responsibility of the dentist in complete denture construction. J Prosthet Dent 1962;12:637-653.
[7] Martone LC. Clinical application of concepts of functional anatomy and speech science to complete denture prosthodontics. J Prosthet Dent 1963;13:20

[8] Boucher CO, Hickey JC, Zarb GA. $7^{\text {th }}$ ED. Prosthodontic treatment for complete denture patients. Delhi: CBS Publishers and Distributors; 1990.

[9] Solomon E, Arunachalam K. The incisive papilla: A significant landmark in prosthodontics. J Indian Prosthodont Soc 2012;12(4):236-247.

[10] Ortman H, Tsao D. Relationship of the incisive papilla to the maxillary central incisors. J Prosthet Dent 1979;42(5):492-496. 